\title{
ANATOMIA DO TUBO DIGESTIVO DE ADULTOS DE ONCIDERES CERVINA (COLEOPTERA, CERAMB YCIDAE)
}

Iraide de Souza Gonçalves ${ }^{1}$

\begin{abstract}
Anatomical study of the alimentary canal and excretory system of the adult of Oncideres cervina are given and illustrated.

\section{INTRODUÇÃO}

A sistemática de Cerambycidae baseia-se principalmente em caracteres morfológicos externos. Bibliografia sobre anatomia interna de cerambicideos é escassa. Poucos autores estudaram o canal alimentar desses insetos. Esse trabalho visa contribuir para as relações filogenéticas das espécies brasileiras.

KONTKANEN (1932) descreveu o tubo digestivo da larva de Acanthocinus aedilis. BUGNION (1933) relatou sucintamente o canal alimentar de fêmeas de Lptura cordigera. JUDD (1949) estudou o estomodeo de adultos de Tetraopes tetraophthalmus e relatou minuciosamente a região estomodeal proventricular. UMEYA (1960) apenas ilustrou o tubo digestivo de machos de Leptura vicaria e Anoplophora melasiaca. BENHAM (1970) fez um estudo comparativo do canal alimentar de larvas, pupas e adultos de Prionus laticollis. DAJOZ (1970) fez uma descrição sumária em relação ao trato intestinal de larvas de Ergates faber. SILVA (1975 e 1976) estudou o tubo digestivo de larvas de Oncideres saga saga. SILVA \& SOUZA (1981) descreveram os aspectos ultraestruturais do mesêntero anterior das larvas de Oncideres saga saga. SOUZA et alii (1985) estudaram as características ultraestruturais do mesêntero posterior das larvas de Oncideres saga saga.
\end{abstract}

\section{MATERIAL E MÉTODOS}

Machos e fêmeas de Oncideres cervina coletados em Carambeí, município de Castro, Paraná, Brasil, foram anestesiados com éter e dissecados sob microscópio estereoscópico (Wild M-5). Com tesoura seccionamos as patas, asas e antenas. Sob solução fisiológica gelada, contida numa placa de Petri com parafina no fundo, cortamos a calota dorsal da cápsula cefálica, os tergitos torácicos e abdominais. Extirpamos o vaso dorsal, gordura, traquéias, músculos e gônadas, deixando, em vista dorsal, o canal alimentar a descoberto desde a faringe até o reto. Através de dissecções ventro-longitudinais foi possível observar a parte ventral do intestino. Para observarmos alguns detalhes removemos o canal alimentar e o distendemos. Confeccionamos os desenhos com câmara clara acoplada ao referido microscópio.

1. Departamento de Biologia Celular. Universidade Federal do Paraná, Curitiba-PR, Brasil. 
Para examinarmos a ornamentaçao da superficie intestinal interna utilizamos a técnica a seguir. Anestesiamos os exemplares, cortamos patas, antenas e asas, nos seus pontos de inserção, mergulhando-os a seguir em solução aquosa de formol a $10 \%$ num periodo de 48 horas. Isolamos os tubos digestivos e seccionamos longitudinalmente o estomodeo e proctodeo, ambos dotados de cutícula quitinosa. Distendemos os segmentos intestinais entre lâmina e lamínula no próprio líquido fixador e os analisamos ao microscópio ótico.

\section{RESULTADOS}

O canal alimentar de Oncideres cenvina de acordo com sua origem, estrutura e função está dividido em três partes: estomodeo, de origem ectodérmica, mesêntero que é endodermal e proctodeo, também ectodérmico.

1. Estomodeo. Devido à sua origem embriológica, a partir de uma invaginação da parede anterior do corpo, apresenta um revestimento interno que corresponde a uma camada quitinosa, a cutícula. Tal camada é contínua com a cavidade bucal e o exoesqueleto. Inicia-se na boca e termina na parte posterior da cápsula cefálica, um pouco antes ou ao nível do forâmen magno. Canal pouco desenvolvido que consta da faringe (Figs. 1 e 2 FA) e esôfago (ES) além da válvula cardíaca (VC).

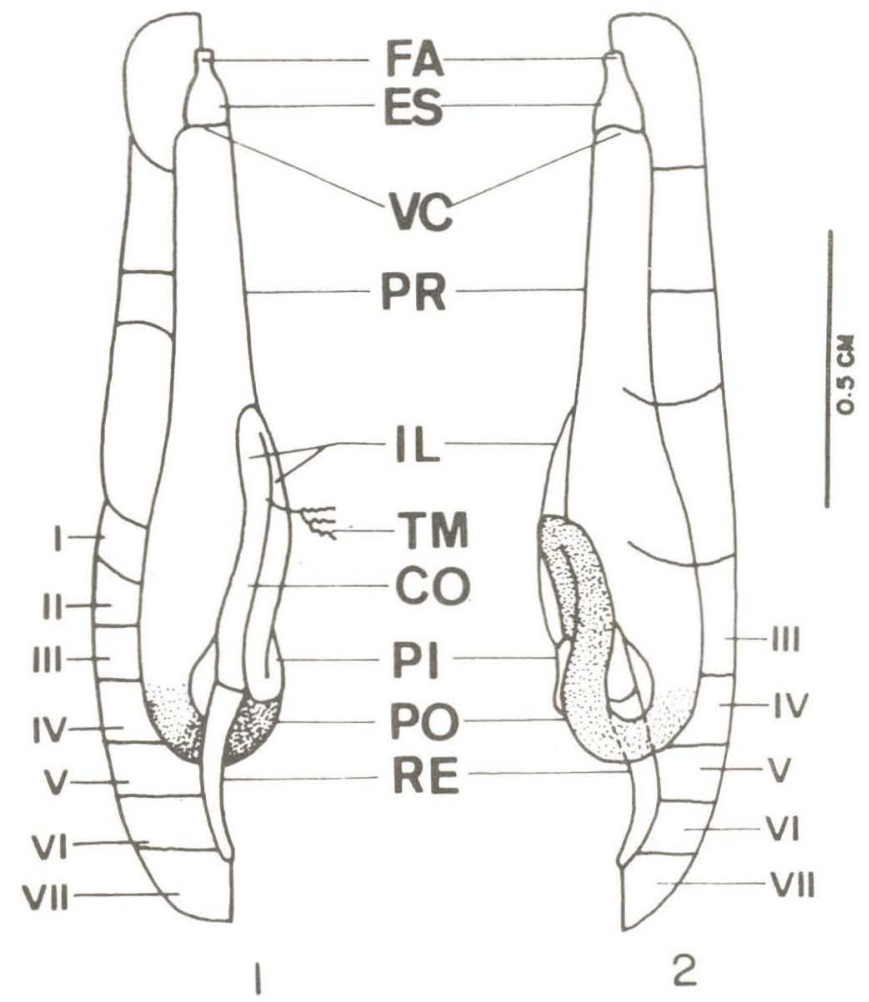

Oncideres cervina (macho): 1 - vista dorsal do tubo digestivo; 2 - idem, ventral; CO, cólon; ES, esôfago; FA, faringe; IL, íleo; PI, piloro; PO, posmesêntero; PR, promesêntero; RE, reto; TM, tubos de Malpighi; VC, válvula cárdica. 
Faringe. Estrutura tubular curta que se localiza entre o gânglio frontal e o cérebro (Figs. 1 e 2, FA). Inicia-se posteriormente à boca e se abre no esôfago através de leve constrição. A face externa desse órgão apresenta cinco pares de músculos dilatadores. $\mathrm{O}$ primeiro par é látero-dorsal e inserido na região anterior da faringe; o segundo, muito poderoso, de modo que cada músculo consta de 4 a 5 feixes seqüenciais, é de inserção meso-dorsal e se localiza nas regiões mediana e posterior do órgão; os músculos do terceiro par, também dorsais, são de pequeno diâmetro e se situam lateralmente ao nível das extremidades anteriores dos músculos precedentes; o quarto par está representado por pequenos músculos meso-ventrais inseridos no bordo orgânico anterior; os do quinto par, formados por três ou quatro feixes, são látero-ventrais e de inserção orgãnica poste rior. A forte quitinização da cutícula confere uma coloração amarela ao órgão que pode ser percebida externamente através de sua parede. A superfície externa dessa última mostra um aspecto estriado devido à poderosa camada de músculos de arranjo circular. A cutícula faringeana é dotada de diminutas escamas quitinosas (visíveis a microscópio ótico a 100x) que diferem levemente de tamanho entre si e se dispõem de forma imbricada, tendo aparência semelhante às escamas de um peixe (Fig. 5). Cada escama prendese à camada cuticular através de seu bordo anterior, enquanto que o posterior é livre e apresenta um pequeno espinho voltado em direção ao esôfago. A continuidade dessas estruturas quitinosas é interrompida, vez por outra, pela presença de volumosos tubérculos isolados que se salientam para o lúmen intestinal (Fig. 6). Tais elementos são dotados de um forte espinho encurvado e de direção posterior.

Esôfago. Órgão pouco desenvolvido que sucede a faringe (Figs, 1 e 2, ES). O calibre esofagiano aumenta gradativamente ao longo do seu comprimento, de modo que a parte orgânica posterior apresenta maior diâmetro. Esta última invagina-se pouco profundamente no extremo anterior do promesêntero e dá origem à válvula cárdica (Figs. I e 2, VC). A superfície externa da parede do esôfago, assim como a da faringe, mostra estriações transversais causadas pela presença de fibras musculares de disposição circular. A interna apresenta seis pregas longitudinais desenvolvidas. A cuticula dessas elevações é provida de poderosos espinhos (visíveis em microscópio fotônico a 40x), pontiagudos e de direção posterior, que diferem entre si tanto em relação ao tamanho como também em aspecto (Fig. 7). Espinhos maiores são encontrados na extremidade esofagiana anterior. Esses diminuem gradativamente de tamanho ao longo do órgão, de modo que os menores são encontrados no extremo posterior do órgão.

Válvula cárdica. É uma prega circular, marcada externamente por um sulco, que tem origem na extremidade posterior do esôfago e penetra na região anterior do promesêntero (Fig. 1 e 2 VC). Dois folhetos, o interno e o externo, constituem a sua parede. O primeiro é uma continuação direta da extremidade posterior do esôfago que se invagina pouco profundamente no extremo anterior do promesêntero e se dobra sobre si mesmo voltando como folheto externo até o ponto de origem, onde se une ao promesêntero. A superfície interna do primeiro folheto é dotada de seis pregas longitudinais que são contínuas com as elevações esofagianas. O folheto externo é destituido de pregas. A cutícula de ambos os folhetos é inerme.

2. Mesêntero. Também designado de ventrículo (SNODGRASS, 1935) é o segmento intestinal mais desenvolvido e se divide em duas partes, a anterior, promesentero e a posterior, posmesêntero (Figs. 1 e 2, PR e PO). A primeira parte inicia-se na região cefálica posterior e se dirige no sentido ântero-posterior ao longo da linha média do corpo do inseto até o metatórax. A partir desse ponto desloca-se levemente à esquerda do eixo corporal e prossegue em direção posterior até o quarto segmento do abdome, onde se 
continua no posmesêntero (Figs. 1 e 2, PR). A parte inicial desse último prossegue à esquerda e posteriormente até o quinto segmento abdominal, quando se curva à direita, passando pelo eixo médio do corpo, ao nível desse mesmo segmento (Fig. 1, PO). Desse ponto o posmesêntero se volta em direção cefálica, constituindo assim seu ramo ascendente que atinge o metatórax (Fig. 2, PO). Nesse local curva-se em direção posterior, originando seu ramo descendente para, ao nível do terceiro segmento abdominal, unir-se ao primeiro órgão do proctodeo, o piloro (Fig. 2, PI). Em seu percurso tortuoso, o posmesêntero descreve duas alças intestinais. A primeira delas é côncava no sentido ânteroposterior enquanto que a segunda é, nesse mesmo sentido, convexa (Fig. 2, PO). Observou-se que o trajeto do promesêntero não apresenta dimorfismo sexual enquanto que o posmesêntero pode variar entre exemplares do mesmo assim como de diferentes sexos. As modificações observadas referem-se ao percurso de ambos os ramos posmesentéricos.

A) Ramo ascendente:

- Paralelo e à direita do eixo do corpo (Fig. 2).

- Metade anterior do ramo à direita e a outra, posterior, ao longo do eixo corporal.

- 3/4 anteriores do ramo à direita e paralelo ao eixo do corpo; $1 / 4$ posterior inclinado obliquamente em direção ao referido eixo.

B) Ramo descendente:

- Parte meso-longitudinal do ramo sobre a região posterior do ramo ascendente e à outra à direita do referido ramo (Fig. 2).

- Sobre a região posterior do ramo ascendente ao longo de todo seu comprimento.

- Paralelo e à direita da região posterior do ramo ascendente.

- Parte anterior, mediana e posterior do ramo em questão à direita, sobre e à esquerda, respectivamente, da região posterior do ramo ascendente. Desse modo a parte posterior do ramo ascendente e a totalidade do ramo descendente descrevem um percurso de meia laçada.

O promesêntero é, de modo geral, bem mais calibroso que o posmesêntero, apesar do calibre do primeiro variar de modo pronunciado ao longo de sua extensão. A parede promesentérica é fina, tornando-se muitas vezes transparente e destituída de pregas na maioria dos exemplares examinados. Graças à transparência da mesma pode-se perceber a camada muscular circular interna que confere uma estriação transversal ao órgão, poucas fibras musculares longitudinais externas, distanciadas entre si e contínuas com o estomodeo, além de pequenas elevações arredondadas, pouco salientes, de esparsa distribuição e difíceis de serem percebidas $\mathrm{O}$ posmesêntero é menos calibroso que o promesêntero. Sua parede, de maior espessura em relação à promesentérica, apresenta elevações arredondadas maiores, mais salientes e contíguas, as quais proporcionam na face externa do órgão um aspecto pontilhado (Figs. 1 e 2, PO).

3. Proctodeo. Deriva embriologicamente de uma invaginação da parede posterior do corpo, logo, assim como o estomodeo, apresenta um revestimento interno, a cutícula. O limite entre o mesêntero e o proctodeo é marcado, externamente, por uma linha circunferencial uniforme que mostra o final da superfície pontilhada do posmesêntero e o começo da superfície lisa do proctodeo (Figs. 2 e 3). Logo acima dessa linha, portanto na extremidade posmesentérica posterior, inserem-se os tubos de Malpighi (Fig. 3, TM). Internamente, a junção mesêntero-proctodeal coıresponde a uma dobra circular em cujo bordo anterior se abrem os referidos canais excretores. O canal proctodeal, de percurso 
convoluto, é de diâmetro variável ao longo de seu comprimento. Inicia-se no extremo posterior do posmesêntero e termina no reto que se abre através do ânus. Divide-se em duas partes: intestino anterior que compreende o piloro, o ileo e o cólon e intestino posterior que está representado pelo reto.

Piloro: Parte anterior do proctodeo que se inicia posteriormente ao limite mesêntero-proctodeal, ao nivel do terceiro segmento abdominal e termina no bordo anterior do quarto segmento (Fig. 2, PI). Apresenta a forma de um cone truncado cuja base está voltada em direção ao posmesêntero (Fig. 3, PI). A posição do piloro é mutável entre ambos ou no mesmo sexo. Observamos as seguintes variações:

- Sobre a região mediana do ramo ascendente do posmesêntero e sob a parte anterior do ramo ascendente do íleo (Figs. 1 e 2, PI).

- À direita da região mediana do ramo ascendente do posmesêntero e à esquerda da parte anterior do ramo ascendente do ileo.

- $\dot{A}$ esquerda da região mediana do ramo ascendente do posmesêntero e sob a parte anterior do ramo ascendente do ileo.

A superfície externa da parede pilórica é dotada de uma camada muscular circular. Tal camada apresenta uma faixa anelar mais espessa na região mediana do órgão que internamente corresponde a uma dobra, a válvula pilórica. Essa última difere da prega encontrada no limite mesêntero-proctodeal pelo fato de ser mais desenvolvida e descontínua. A descontinuidade da dobra valvular decorre da presença de sulcos existentes entre as seis elevações longitudinais que protrudem em direção ao lúmen pilórico. A cutícula do piloro mostra, em toda sua extensão, escamas imbricadas entre si, cujos bordos posteriores, que são livres, apresentam um aspecto serrilhado (Fig. 8). Tal aspecto é decorrente da presença de diminutos espinhos, os quais variam de dois a nove em cada escama e estão voltados em direção caudal.

Íleo. Posteriormente ao piloro, o ileo tem início ao nivel do quarto segmento abdominal, onde se volta em direção cefálica, originando assim seu ramo ascendente, o qual atinge o metatórax (Fig. 1, IL). Nesse local dobra-se posteriormente e dá origem ao seu ramo descendente (Fig. 1, IL). Este último abre-se no cólon, ao nível da região ṕosterior do metatórax (Fig. 1, CO). A região intermediária, em forma de arco, entre ambos os ramos do órgão em questão, apresenta dois músculos longitudinais (Fig. 4, ML). Esses últimos fixam-se na face exterior côncava do arco, ficando soltos na cavidade do corpo sob a veia dorsal e assentados sobre o promesêntero para se inserirem no segundo fragma torácico através de seus tendões. Nas fêmeas os ligamentos ovarianos fundem-se aos referidos tendões. O ileo apresenta diâmetro relativamente constante do longo de sua extensão. Seu percurso varia entre machos, fêmeas, ou ambos. As modificações observadas foram:

- Ramo ascendente paralelo e à direita do cólon (Fig. 1, IL) sobre parte da válvula pilórica e ramo descendente do posmesêntero (Fig. 2 IL) além da região mediana do promesêntero (Fig. 1 IL) ramo descendente paralelo e à esquerda do ascendente e sobre a região mediana do promesêntero (Fig. $1 \mathrm{IL}$ ).

- Dois terços anteriores do ramo ascendente sob o cólon, à direita da válvula pilórica e do ramo descendente do posmesêntero. $\mathrm{O}$ terço posterior, não mais sob o cólon, sobre a região mediana do promesêntero.

- Metade anterior do ramo ascendente sob o cólon e sobre a válvula pilórica e ramo descendente do posmesêntero. Metade posterior à esquerda do cólon e sobre a região mediana do promesêntero. A superfície externa da parede do íleo mostra seis feixes musculares longitudinais eqüidistantes entre si, correspondendo internamente a sul- 
cos pouco profundos. Tais feixes, devido a sua delgadeza, são difíceis de serem observados. O ramo descendente desse órgão mostra a camada muscular muito desenvolvida. A cutícula do íleo é desprovida de omamentação quitinosa.

Cólon. A junção entre o íleo e o cólon aparenta ser marcada pela presença de seis feixes musculares longitudinais, eqüidistantes entre si, que percorrem a superfície externa da parede do órgão em questão (Fig. 4, FM). Tais feixes, contínuos aos existentes na parede do íleo, muito poderosos na parte anterior do cólon, sofrem adelgaçamento progressivo, de modo que, na região orgânica posterior parecem, à primeira vista, inexistentes. Tal fato se deve ao pequeno diâmetro dos feixes nessa região, os quais, próximo ao reto, se desdobram em seus constituintes menores, as fibras. Estas últimas, em conjunto, formam pequenos triângulos musculares cujas bases estão relacionadas com a ampola retal. Desse modo a extremidade posterior de cada feixe mostra um leque triangular diminuto de fibras musculares. Para observar esses detalhes é necessário afastar a membrana peritonial e os tubos de Malpighi. A superfície interna do órgão mostra seis sulcos que correspondem, externamente, aos feixes musculares. Tais fendas, ao nível dos triângulos musculares, são inexistentes. $\mathrm{O}$ cólon, menos desenvolvido que o íleo, tem início à direita do metatórax, um pouco acima da inserção dos tubos de Malpighi e sobre a região mediana do promesêntero (Fig. 1). Prossegue em direção caudal até o quarto segmento abdominal, quando desemboca no reto (Figs. 1 e 2, RE). O percurso do cólon também varia entre exemplares do mesmo e de diferentes sexos:

- Paralelo e à esquerda do ramo ascendente do íleo (Figs. 1, CO).

- Extremo anterior do cólon à esquerda do ramo ascendente do ileo e o restante do órgão sobre o referido ramo.

- Metade anterior do órgão à direita do ramo ascendente do íleo e a posterior sobre o citado ramo.

A cutícula do cólon é inerme.

Reto. Inicia-se posteriormente ao cólon e ao nível do quarto segmento abdominal (Figs. 1 e 2, RE). É uma estrutura tubular desenvolvida cujo calibre, inicialmente amplo, diminui de modo gradativo no sentido ântero-posterior de forma a terminar num pequeno orifício, o ânus (Fig. 4, RE). Seis feixes musculares longitudinais prendem-se na superfície externa do órgão, exclusivamente nos extremos anterior e posterior do mesmo. Dessa maneira esses músculos, em sua maior extensão, ficam apenas justapostos à parede retal. Todos os feixes ramificam-se em suas regiōes medianas e seus ramos vão se inserir no nono segmento abdominal. Uma poderosa camada muscular circularmente disposta, situada sob os referidos feixes longitudinais, percorre toda a superfície da parede retal. Esta última, em sua face interna, apresenta seis pregas longitudinais achatadas que estão separadas entre si por seis sulcos profundos. Cada uma dessas fendas pode ser observada através da superficie retal externa como duas linhas mais claras paralelamente dispostas ao longo de todo órgão. Nos extremos dessas linhas fixam-se os seis feixes musculares anteriormente descritos. A cutícula desse componente proctodeal mostra tubérculos pequenos e esparsos que são dotados em suas regiões centrais de um espinho quitinoso encurvado e de direção posterior (Fig. 9). Comparando-se as figuras 9 e 6 percebe-se que os tubérculos retais, com seus espinhos, são muito semelhantes aos faringeanos. O percurso do reto apresenta variações como nos órgãos precedentes.

- Extremos anterior e posterior do órgão ao nível do eixo corporal, região mediana à esquerda desse eixo (Figs. 1 e 2, RE).

- Ao longo do eixo do corpo em toda sua extensão. 
Vol. $7(1-2), 1990$

- Extremos retais anterior e posterior ao longo da linha média do corpo; região mediana à direita dessa linha.
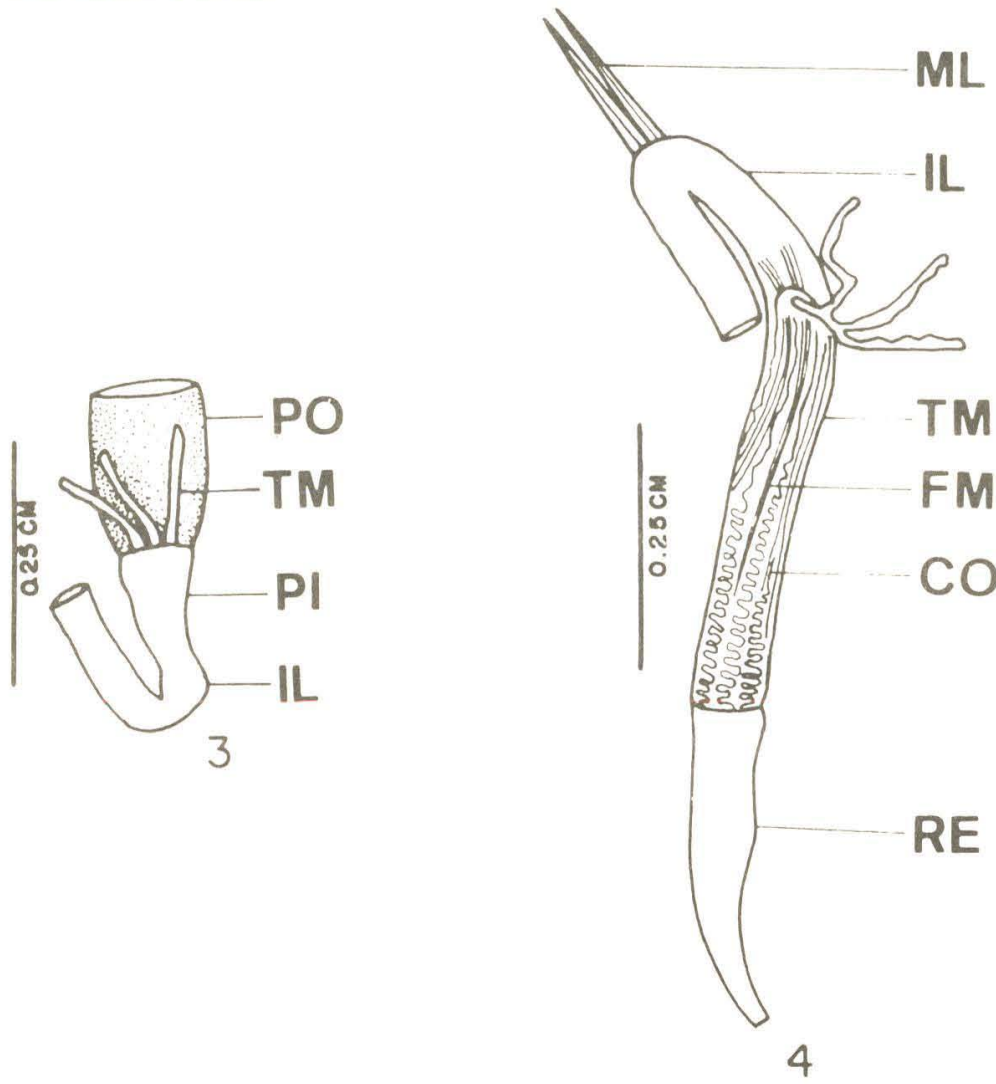

Oncideres cervina (macho): 3 e 4, detalhes do proctodeo; CO, cólon; FM, feixes musculares; IL, íleo; ML, músculos longitudinais; PI, piloro; $\mathrm{PO}$, posmesêntero; RE, reto; TM, tubos de Malpighi.

Tubos de Malpighi. Na extremidade posterior do mesêntero, ou seja, acima da linha anelar que marca externamente a junção mesêntero-proctodeal, desembocam, independentemente, seis tubos de Malpighi. Esses últimos estão dispostos em dois grupos, um dorsal e outro ventral, cada qual constituído por três tubos eqüidistantes entre si e inseridos no mesmo nível (Fig. 3, TM). Esses canais excretores, de percurso muito variável entre os diversos exemplares observados, atingem o tórax ao nível do terceiro ou segundo segmento torácico. Percorrem a cavidade abdominal e se entrelaçam com o aparelho reprodutor dos espécimens de modo que alcançam a parte posterior do abdome chegando, algumas vezes, ao nível do reto. Retornam às proximidades do cólon e, nesse local, dois tubos pertencentes ao mesmo grupo fundem-se em um único o qual, após um curto trajeto coalesce com o tubo restante do grupo formando um canal comum que se insere na região ântero-lateral do cólon (Fig. 4, TM). Esse mesmo arranjo ocorre em ambos os grupos de canais excretores. Uma vez que os dois canais se inserem no cólon, eles se subdividem, cada qual originando novamente três tubos de Malpighi. Esses últimos 
aderem-se na superfície externa da parede do cólon, entre os feixes musculares longitudinais, sob a membrana peritonial e terminam em fundo cego no bordo posterior desse mesmo órgão. Abaixo do peritônio os canais excretores têm, inicialmente, um percurso levemente sinuoso, seguindo-se de pequenas alças para, na região posterior do cólon, apresentarem um trajeto muito tortuoso, marcado por alças desenvolvidas e justapostas entre si (Fig. 4, TM). Os seis tubos de Malpighi, de modo geral, são mais calibrosos e levemente sinuosos nas proximidades do limite mesêntero-proctodeal. Anteriormente aos coalescimentos e à inserção na parede do cólon, a totalidade desses canais mostra menor diâmetro e aspecto varicoso.
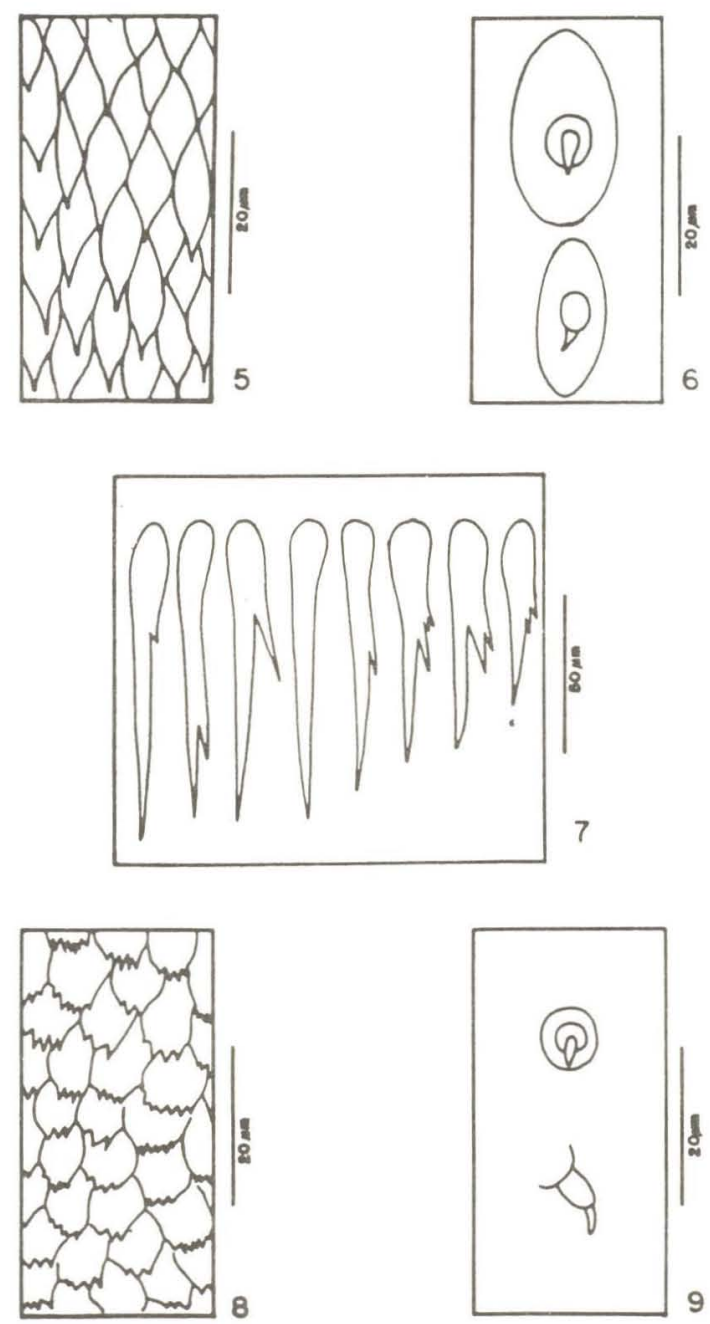

Oncideres cervina (macho): 5 e 6 , ornamentação quitinosa da faringe; 7 , ornamentação quitinosa do esôfago; 8 , ornamentação quitinosa do piloro; 9 , ornamentação quitinosa do reto. 


\section{DISCUSSÃo}

O estomodeo de machos e fêmeas de $O$. cervina, assim como das fêmeas de $L$. cordigera (BUGNION, 1933) e larvas de $O$. saga saga (SILVA, 1975 e 1976), consta apenas da faringe e esôfago; não segue portanto o arranjo clássico (faringe, esôfago, pago ou ingluvium e proventrículo) descrito por SNODGRASS (1935). A presença de papo foi divulgada nos adultos de $T$. tetraophthalmus (JUDD, 1949); nas larvas, pupas e adultos de P. laticollis (BENHAM, 1970); nas larvas de A. aedilis (KONTKANEM, 1932) e de E. faber (DAJOZ, 1970). A ausência de proventrículo foi constatada por KONTKANEN (1932), BENHAM (1970) e DAJOZ (1970). JUDD (1949) descreveu detalhadamente a região proventricular de $T$. tetraophthalmus. A válvula cárdica de $O$. cervina assim como de $O$. saga saga (SILVA, 1975 e 1976) consta de uma dobra anelar de dupla parede que obstrui parcialmente a luz intestinal. Em T. tetraophthalmus (JUDD, 1949) a válvula em questão, com aspecto de roseta, fecha quase que totalmente o lúmen do estomodeo. KONTKANEN (1932) apenas mencionou a presença da referida válvula. BUGNION (1933), NENHAM (1970) e DAJOZ (1970) não fizeram referência a esse componente estomodeal valvular. A cutícula da faringe e esôfago de $O$. cervina é dotada de ornamentação quitinosa representada por escamas, espinhos e tubérculos. A faringe de $O$. saga saga (SILVA, 1975 e 1976) e a de A. aedilis (KONTKANEN, 1932) mostraram, respectivamente, espinhos e dentes quitinosos; esôfago inerme em ambas as espécies. A cutícula da válvula cárdica de O. cervina e O. saga saga (SILVA, 1976) é destituída de ornámentação; JUDD (1949) constatou a presença de espinhos achatados na referida válvula de T. tetraophthalmus.

O mesêntero de $O$. cervina, assim como os de $O$. saga saga (SILVA, 1975), $A$. aedilis (KONTKANEN, 1932) e E. faber (DAJOZ, 1970) é o segmento intestinal mais desenvolvido quando comparado ao estomodeo e proctodeo. Em $L$. cordigera e P. laticollis (BENHAM, 1970) o ventrículo mostrou pequeno desenvolvimento; destacou-se o proctodeo. $\mathrm{O}$ intestino médio de $O$. cervina subdivide-se em duas regiões, o pro e o posmesêntero. Tal terminologia foi usada para Reduviidae (LACOMBE, 1957) e Cerambycidae (SILVA, 1975 e 1976). Em O. cervina o promesêntero mostra-se mais calibroso e de percurso aproximadamente retilíneo enquanto que o posmesêntero, de pequeno diâmetro, descreve duas alças em seu trajeto tortuoso. Idênticas características mesentéricas foram descritas para $A$. aedilis (KONTKANEN, 1932) e $O$. saga saga (SILVA, 1975). O percurso do ventrículo de O. cervina é semelhante ao de E. faber (DAJOZ. 1970); nessa última espécie o diâmetro mesentérico pouco diferiu ao longo de seu comprimento. Em L. vicaria (UMEYA, 1960) o pro e posmesêntero, a mbos com mesmo calibre, apresentaram percurso retilíneo. Esse mesmo trajeto foi observado no mesêntero das larvas, pupas e adultos de $P$. laticollis (BENHAM, 1970). Nas pupas e adultos dessa última espécie, o promesêntero mostrou-se excepcionalmente mais numeroso que o posmesêntero; nas larvas a diferença de calibre entre ambos segmentos mesentéricos não foi tão pronunciada. A parede do ventrículo de $O$. cervina é destituída de pregas. $\operatorname{Em} O$. saga saga (SILVA, 1975) tais estruturas foram observadas apenas no promesêntero; posmesêntero liso. Através das ilustrações pudemos observar que a parede do mesêntero da larva de $P$. laticollis (BENHAM, 1970) mostra pregas profundas enquanto que a do adulto nos pareceu destituída das mesmas. A superfície extema da parede do promesêntero de $O$. cervina é dotada de pequeníssimas elevações arredondadas, pouco protuberantes e de distribuição esparsa; no posmesêntero tais elevações são maiores, mais salientes e contíguas entre si. Acreditamos que as pequenas protuberâncias promesentéri- 
cas sejam decorrentes da compressão dos pequenos ninhios de células epiteliais regenerativas (SILVA \& SOUZA, 1981); as elevações posmesentéricas provavelmente são fruto da presença de criptas epiteliais não regenerativas (SOUZA et ali, 1985).

O proctodeo de $O$. cervina consta de quatro segmentos: piloro, ileo, cólon e reto. $O$ piloro de $O$. cervina é, externamente, difícil de ser diferenciado; internamente sua individualização é facilmente perceptível, pois apresenta uma semelhança marcante às descrições de SNODGRASS (1935) para os Coleoptera. Não foi mencionado a existência de uma região pilórica no proctodeo de Cerambycidae (KONTKANEN, 1932; BUGNION, 1933; DAJOZ, 1970; BENHAM, 1970 e SILVA, 1975 e 1976). O ileo de $O$. cervina é o segmento proctodeal mais desenvolvido e está composto por dois ramos; o ascendente e o descendente; este último mais curto. Idênticas características anatômicas foram descritas para o referido órgão em O. saga saga (SILVA, 1975). Nas larvas de A. aedilis (KONTKANEN, 1932) e $P$. laticollis (BENHAM, 1970) ambos os ramos do ileo mostraram aproximadamente a mesma extensão longitudinal. O cólon de $O$. cervina consta de um tubo de diâmetro aproximadamente constante cuja superfície externa de sua parede é dotada de seis poderosos feixes musculares longitudinais, eqüidistantes entre si e dispostos ao longo de todo o órgão; nos espaços compreendidos entre os tais feixes associam-se os tubos de Malpighi sinuosamente dispostos. Essas mesmas características foram descritas para o cólon de A. aedilis (KONTKANEN, 1932) e O. saga saga (SILVA, 1975 e 1976) exceto que nas duas espécies em questão os seis feixes musculares foram observadós apenas na região anterior do órgão. O reto de $O$. cervina é destituído de dobras logo, percurso não tortuoso. Em L. vicara e $A$. malasiaca (UMEYA, 1960) assim como nas larvas, pupas e adultos de P. laticollis (BENHAM, 1970) o referido órgão mostrou trajeto serpeante. A cutícula do reto de $O$. cervina, ao contrário dos dois órgãos que o precedem, é dotada de ornamentação quitinosa. Nos trabalhos que consultamos sobre Cerambycidae não foi mencionado a existência de omamentação quitinosa retal.

Os tubos de Malpighi de $O$. cervina são em número de seis e dispustos em dois grupos de três que se abrem independentemnte no limite mesêntero-proctodeal. Essas mesmas características foram divulgadas por KONTKANEN (1932), BUGNION (1933), UMEYA (1960), BENHAM (1970), DAJOZ (1970) e SILVA (1975 e 1976). As partes distais dos citados canais excretores de $O$. cervina estão intimamente associados a superfície externa da parede do cólon. Tal fato coincide com as observações feitas por UMEYA (1960), BENHAM (1970) e SILVA (1975 e 1976). Em A. aedilis (KONTKANEN, 1932) as partes distais dos tubos de Malpighi estão associadas ao reto.

\section{AGRADECIMENTOS}

Ao professor Renato Marinoni pela sugestão do trabalho e ao professor Fioravante Giacomel pelos insetos fornecidos. 
Vol. $7(1-2), 1990$

\section{REFERÊNCIAS BIBLIOGRÁFICAS}

BENHAM், G.S., Jr. 1970. Gross morphology and transformation of the digestive tract of Prionus laticollis (Coleoptera, Cerambycidae). Ann. Entomol. Soc. Ame r. 63 (5): 1413-1419.

BUGNION, E. 1933. La leptura cordigera biologie, anatomie, physiologie. Mem. Soc. Vaudoise Sci. Natur. 4 (6): 329-359.

DAJOZ, R. 1970. Quelques caractères morphologiques et anatomiques de la larve d' Ergates faber (Coleoptera, Cerambycidae). Ann. Soc. Ent. Fr. (N S.) 6 (2): 417-423.

JUDD, W.W. 1949. The proventricular region of Tetraopes tetraophthalmus Forst. (Coleoptera, Cerambycidae), Can. J. Res. Ottawa 27 (D): 195-199.

KONTKANEN, P. 1932. On the larval digestive tract of Acanthocinus aedilis L. (Colcoptera, Cerambycidae). Ann. Bot. Soc. Zool. - Bot. Fenn. "Vanamo" 12 (4): 91-98.

LACOMBE, D. 1957. Estudos anatômicos e histológicos sobre a subf amılia Triatominae (Heteroptera, Reduviidae). Mem. Inst. Osw. Cruz 55 (1):69-110.

SILVA, I. 1975. Morfologia do tubo digestivo da larva de Oncideres saga saga (Dalman, 1823) (Coleoptera, Cerambycidae). Acta Biol. Par. 4 (3, 4): 227-239.

SILVA, I. 1976. Estrutura histológica do tubo digestivo da larva de Oncideres saga saga (Dalman, 1823) (Coleoptera, Cerambucidae). Acta Biol. Par. 5 (1, 2): 99-106.

SILVA, I. \& V.B.V. SOUZA 1981 . Ultrastructural aspects of the anterior mid gut of Oncideres saga saga (Dalman, 1823) - larva (Coleoptera, Cerambycidae). Rev. bras. Ent. 25 (2): 103-112.

SNODGRASS, R.E. 1935. Principles of insect morphology. McGraw-Hill, Book Company, New York and Lonior

SOUZA, V.B.V.; I. DA SILVA; R.M.P.C. DA SILVA \& Z.M.P. KASSMAYER. 1985. Aspectos ultraestruturais do mesêntero de Oncideres saga saga (Dalman, 1823) - larva (Coleoptera, Cerambycidae) - criptas. Rev. Setor Ciênc. Agr. 7:67-74.

UMEYA, K. 1960. A comparative morphology of the alimentary tract in the adults of Lamellicornbeetles (Coleoptera). Mem. Fac. Agr. Hokkaido Univ. 3 (4) : 60-113. 